\title{
PENGARUH KEPEMIMPINAN BUDAYA ORGANISASI DAN KOMPETENSI TERHADAP KINERJA KARYAWAN PT. TELKOM AKSES WITEL MEDAN
}

\author{
INFLUENCE OF LEADRESHIP ORGANIZATIONAL CULTURE AND \\ COMPETENCE ON EMPLOYEE PERFORMANCE PT. TELKOM ACCESS \\ WITEL MEDAN
}

\author{
Muhammad Ferry $^{1^{*)}}$ Dedi Yuliantoni Manalu ${ }^{2)}$ Pratiwi Pangestu ${ }^{3)}$ Maya Agustina \\ Tanjung ${ }^{4)}$ \\ ${ }^{1,2,3,4}$ Fakultas Ekonomi, Universitas Prima Indonesia \\ ${ }^{1}$ Email: muhammadferry134@gmail.com
}

\begin{abstract}
ABSTRAK
Sumber daya manusia merupakan aset yang sangat penting di dalam suatu organisasi. Dalam hal ini kinerja karyawan merupakan hal pokok yang sangat di perhatikan perusahaan dalam menjalankan tugas, untuk persoalan tersebut menuntut manajemen perusahaan untuk merencanakan, budaya organisasi, dan melakukan pengawasan kompetensi terhadap kinerja karyawan secara tepat dan berhasil. Penelitian ini bertujuan untuk menganalisis pengaruh kepemimpinan, budaya organisasi, dan kompetensi terhadap kinerja karyawan pada PT. Telkom Akses Witel Medan. Metode yang digunakan dalam penelitian ini pendekatan kuantitatif, pengumpulan data dilakukan dengan kuisioner, wawancara, dan dokumentasi. Analisis data yang digunakan adalah regresi linier berganda. Populasi jumlah seluruh karyawan adalah 376 orang. Dalam pengambilan sampel mengunakan rumus slovin 193 orang. Hasil penelitian menunjukan bahwa kepemimpinan berpengaruh Positf dan signifikan terhadap kinerja karyawan, budaya organisasi berpengaruh positif dan signifikan terhadap kinerja karyawan, kompetensi berpengaruh positif dan signifikan terhadap kinerja karyawan, dalam pengujian secara simultan Hal ini menujukan bahwa kepemimpinan, budaya organisasi dan kompetensi berpengaruh positif dan signifikan terhadap kinerja karywan PT. Telkom Akses Witel Medan. Hasil koefisien determinasi menunjukan bahwa 16,7\% variasi tabel kinerja (Y), sedangkan sisanya $83,3 \%$ adalah Variabel bebas lainnya yang tidak di jelaskan dalam penelitian ini.
\end{abstract}

Kata Kunci: Kepemimpinan, Budaya Organisasi, Kompetensi, Kinerja

\begin{abstract}
ABSTRACK
Human resources are factors that play an important role in an organization. In this case, the employee's perfomances is a staple that is very important in the company's task, for the issue demand the management of the company's task to plan, organizational culture, and supervise the competency of employee's perfomance approprialy and successfully. This research aims to analyse the influence of leadership, organizational culture and competence on the perfomance of employee's at PT Telkom Access Witel Medan. In this study using quantitative approach methods. Data collection is done with the questionnair, interviews, dan domucentation. The analysis of the data used is a double linier regression analysis. The populatioan of the total employees was 376 people. In sampling using a formula slovin 193 people. The result of the analysis of the research that shows leadership is very positive and significant to the employee's perfomances, the
\end{abstract}


P-ISSN 2580 - 7781

E-ISSN 2615 - 3238

organizational culture is very positive and significant to the employee's perfomance, the competency is positive an significant to the employee's perfomance, in simultaneous testing this suggests that the leadership, organizational culture, and competence are positive and significant to the performance of PT Telkom Access Witel Medan. The result coefficient indicates that the $16.7 \%$ perfomance table variation $(y)$ while the remaining $83,3 \%$ is another free variable that is not describe in this study.

Keywords: leadership, organizational culture, competence, employee.

\section{PENDAHULUAN}

Di dalam organisasi sumber daya manusia merupakan faktor yang sangat penting. sebab yang dapat menggerakkan sumber daya lainnya hanyalah manusia itu sendiri. Agar organisasi sejalan dengan tuntutan yang dihadapi dan mampu menjawab berbagai tantangan yang ada, organisasi harus mampu menggunakan sember daya manusia yang dimilikinya dengan sebaik mungkin

PT. Telekomunikasi indonesia, Tbk memiliki anak perusahaan yaitu PT. Telkom Akses (PTTA). Dimana sahamnya dimiliki sepenuhnya oleh Telkom. PT. Telkom Akses merupakan perusashaan yang bergerak dibidang konstruksi pembangunan dan memanage service infrastruktur jaringan. Pada tanggal 12 Desember 2012 PT. Telkom Akses telah berdiri. dan terdiri dari tujuh divisi, salah satunya adalah disumatera utara atau Divisi Regional I, Yang berada di jalan Gaharu No. 1 Medan. Hal ini penulis pilih karena penulis melakukan penelitian di kantor Telkom Witel Medan. Pada saat iniperusahaan sedang mengalami penurunan penjualan, dan ini terjadi karena menurunnya kinerja karyawan .

Dari data penjualan pertahun terlihat pada 2014 data realiasi sebesar 29.130, untuk data di tahun berikutnya pada 2015 sebesar 24.239, dan sedangkan pada tahun tahun 2016 sebesar 17.350. dan target perusahaan pertahunnya adalah penjualan terendah terjadi pada tahun 2016 hal ini di karenakan kurang gencarnya karyawan dalam melakukan promosi dan di dalam satu tahun tersebut ering mengalami gangguan akibat cuaca yang buruk seperti hujan yang di sertai angin kencang yang dapat menganggu jaringan dan proses pemasangan untuk menjaga seluruh keselamtan karyawan dalam proses pemasangan.

Kepemimpinan adalah teknik mempengaruhi sekelompok orang dalam berbagai kegiatannya yang terorganisir dalam usaha mereka menetapkan dan mencapai target. Menurut Fahmi (2016:141) hasil kinerja para karyawan sangat dipengaruhi 
oleh seorang pemimpin. meningkatan kualitas kinerja pegawai memiliki pengaruh untuk menciptaan kualitas kinerja agar sesuai dengan harapan. Menurut Umam (2010:268) dalam kenyataan, kepuasan kerja dan moral, keamanan, kualitas semangat kerja, dan tingkat prestasi suatu organisasi dapat di pengaruhi para pemimpin. Berdasarkan teori diatas kepemimpinan sangat mempengaruhi hasil kinerja karyawan di dalam suatu organisasi dalam mencapai kualitas kinerja dan untuk mencapai tingkat prestasi suatu organisasi agar maksimal. Pada PT Telkom Akses Witel Medan pemimpin belum mampu berinteraksi dengan baik terhadap bawahannya dan lebih membawa sikap egonya dalam memimpin. Masalah lain juga yaitu pemimpin memaksa karyawan untuk bekerja pada hari libur ketika ada target yang harus dicapai.

Budaya organisasi adalah menjadi nilai pedoman untuk mengurangi permasalahan eksternal dan usaha penyesuaian integrasi kedalam organisasi bagi sumber daya manusia, karena itu seluruh bagian organisasi diwajibkan untuk memahami nilai yang ada dan sebagaimana mereka harus berkarakter atau bertingkah laku. Menurut Wibowo (2017:193) apabila organisasi mau menerima pengenalan terhadap proses, maka hal tersebut terjadi karna dibentuknya oleh budayanya, budaya organisasi memberi signal apakah pendekatan tertentu pada penilaian kinerja akan di terima atau ditolak. Menurut Sutrisno mengatakan budaya organisasi suatu alat manajemen yang sangat berpengaruh dan sebagai pendorong bagi setiap pegawai agar berperilaku, dedikatif, produktif, dan positif, maka nilai budaya itu tidak tampak, tetapi merupakan suatu kekuatan untuk mendorong perilaku agar menghasilkan efektivitas yang baik. Budaya Organisasi sangat berpengaruh terhadap kinerja karyawan agar dapat menimbulkan budaya yang sangat baik di dalam setiap organisasi secara baik untuk mencapai proses yang diinginkan oleh perusahaan dan pemimpin. Hasil survei awal di PT Telkom Akses Witel Medan pada tanggal 12 februari 2019 dengan melakukan wawancara didapatkan informasi bahwa budaya organisasi yang diterapkan oleh PT Telkom Akses Witel Medan yaitu, discipline, quality, integrity, dan totality. belum semua karyawan melaksanakan budaya organisasi 
P-ISSN 2580 - 7781

E-ISSN 2615 - 3238

perusahaan dengan baik, terutama pada disiplin, sebagai contoh waktu tiba yang ditetapkan untuk karyawan yang bekerja di bagian kantor adalah pukul 08.00 WIB pagi akan tetapi pada kenyataannya banyak karyawan yang datang tidak tepat waktu pada saat masuk kantor.

Kompetensi adalah keterampilan, pengetahuan, sikap dasar, serta nilai yang dicerminkan kedalam kebiasaan berpikir dan bertindak yang sifatnya berkembang, dinamis, kontinyu, serta dapat diraih setiap waktu. Menurut Jamaran (2016:55), kompetensi merupakan sistem manajemen kinerja secara formal untuk pembentukan keterampilan, keahlian dan perilaku karyawan agar berhasil dalam peran pertumbuhan organisasi dimasa depan. Menurut Serdamayanti (2014:127), kompetensi merupakan unsur utama penentu untuk seseorang dalam menghasilakan kinerja yang sangat baik. Dalam situasi kolektif merupakan faktor kunci penentu keberhasilan organisasi. Teori diatas, terlihat sangat berpengaruh terhadap kinerja karyawan. Berdasarkan kinerja karyawan yang ada didalam organisasi, penilaian terhadap kompetensi perlu dilakukan secara objektif. Pada PT Telkom Akses Witel medan kompetensi yang dimiliki karyawan belum maksimal, dimana karyawan masih kurang dalam bidang pelayanan pelanggan, selain itu karyawan belum bekerja dengan sungguh-sungguh, karyawan hanya mengetahui sebatas pekerjaan mereka saja.

Berdasarkan permasalahan pada latar belakang maka peneliti melakukan penelitian dengan judul "Pengaruh Kepemimpinan Budaya Organisasi dan Kompetensi terhadap Kinerja Karyawan pada PTTelkom Akses Witel Medan" dengan tujuan untuk menganalisis pengaruh kepemimpinan, budaya organisasi, dan kompetensi terhadap kinerja karyawan pada PT. Telkom Akses Witel Medan.

\section{METODE PENELITIAN}

Pendekatan kuantitatif digunakan dalam pendekatan penelitian ini. Menurut Sugiono (2012:13), metode kuantitatif merupakan metode penelitian yang berasaskan pandangan positifisme, dan dipakai dalam meneliti sampel atau populasi tertentu, instrumen penelitian digunakan dalam pengumpulan data, analisis data bersifat kuantitatif atau statistik. 
Adapun populasi yang di dapat dari penelitian ini adalah seluruh karyawan yang ada pada PT. Telkom Akses Witel Medan berjumlah 376 responden. Sampel diambil secara acak, tanpa memperhatikan tingkat yang ada tiap populasi, memiliki peluang yang sama dan diketahui untuk terpilihnya subjek, jumlah sampel ditentukan dengan rumus slovin sebnayak 193 responden. Pengumpulan data dengan cara wawancara, kuisioner dan dokumen.

Pengolahan data dengan uji validitas dan reabilitas yang bertujuan untuk mengetahui suatu kusioner valid atau tidak, uji asumsi klasik serta analisis regresi berganda.

Kemampuan model dalam menerangkan variasi variable dependen diukur dengan Koefisien Determinasi $\left(\mathrm{R}^{2}\right)$. Koefisien determinasi memiliki nilai antara nol dan satu. Walaupun nilai Adjusted $R^{2}$ di kehendaki bernilai positif, namun bisa saja nilai Adjusted $R^{2}$ dapat bernilai posistif, uji t dan uji F.

\section{HASIL DAN PEMBAHASAN}

\section{Analisis Statistik Deskriktif}

Pada penelitian di PT. Telkom Akses Witel Medan, variabel bebas (independent variabel) diamati adalah kepemimpinan (X1), Budaya Organisasi (X2), Kompetensi (X3), sedangkan variabel yang terikat (dependent variabel) adalah kinerja (Y), dapat di lihat pada tabel Deskritif Statistik berikut ini:

\begin{tabular}{|l|r|r|r|r|r|}
\hline & N & Minimum & Maximum & Mean & $\begin{array}{c}\text { Std. } \\
\text { Deviation }\end{array}$ \\
\hline KEPEMIMPINAN & 193 & 16 & 40 & 30,24 & 6,298 \\
BUDAYA & 193 & 15 & 40 & 31,60 & 6,638 \\
ORGANISASI & 193 & 18 & 40 & 27,37 & 6,956 \\
KOMPETENSI & 193 & 16 & 40 & 27,48 & 6,337 \\
KINERJA & 193 & & & & \\
Valid N (listwise) & Sumber : Hasil penelitian, 2019 (Data Diolah)
\end{tabular}


P-ISSN 2580 - 7781

E-ISSN 2615 - 3238

Statistik deskriftif berhubungan dengan bagaimana data dapat digambarkan (di deskripsikan) atau di simpulkan. Dari tabel di atas dapat dilihat bahwa nilai rata-rata dari hasil pengukuran variabel Kepemimpinan $\left(\mathrm{X}_{1}\right)$ adalah nilai mean 30.24 dengan standart deviasi 6.298, variabel Budaya Organisasi $\left(\mathrm{X}_{2}\right)$ adalah memiliki nilai rata-rata mean 31.60 dengan standart deviasi 6.638, variabel Kompetensi $\left(\mathrm{X}_{3}\right)$ adalah memiliki nilai rata-rata mean 27.37 dengan standart deviasi 6.956, variabel Kinerja (Y) adalah memiliki nilai rata-rata mean 27.48 dengan standart deviasi 6.337.

\section{Uji Normalitas}

1) Grafik Histogram

\section{Grafik Histogram}

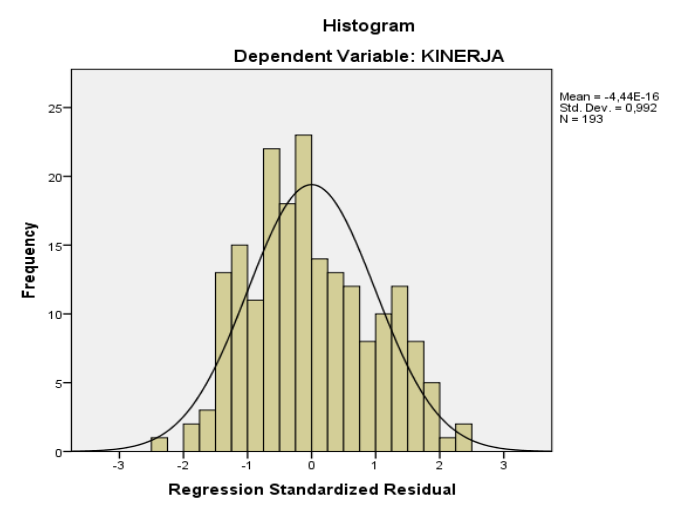

Sumber : Hasil Penelitian, 2019 (Data Diolah)

Berdasarkan gambar diatas, dapat dilihat bahwa grafik histogram data tersebut melenceng ke kanan dan ke kiri, maka pengujian data tersebut dinyatakan berdistribusi normal. 
P-ISSN 2580 - 7781

E-ISSN 2615 - 3238

\section{Grafik Histogram}

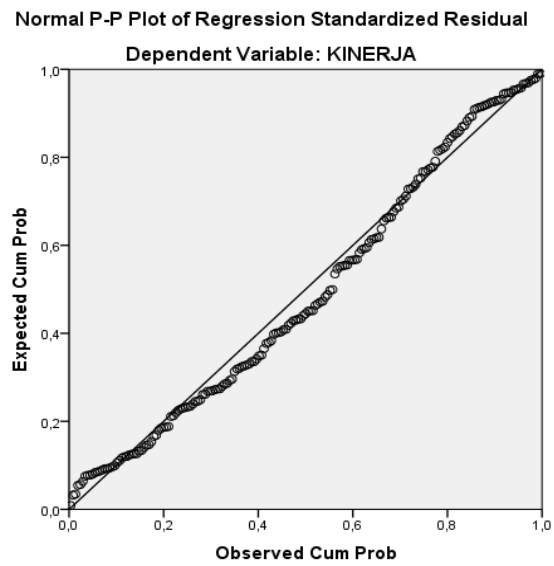

Sumber : Hasil Penelitian, 2019 (Data Diolah)

Bedasarkan gambar normal P.P Plot Of Regresioan Standardized Residul di atas dapat di lihat bahwa data menyebar di sekitar garis diagonal, dan tidak ada data yang letaknya jauh dari garis diagonal tersebut maka dinyatakan data tersebut berdistribusi normal.

2) Analisis Grafik

Tabel Uji Kolmogrov Smirnov

One-Sample Kolmogorov-Smirnov Test

\begin{tabular}{|ll|r|}
\hline & & $\begin{array}{c}\text { Unstandardized } \\
\text { Residual }\end{array}$ \\
\hline $\mathrm{N}$ & Mean & 193 \\
Normal Parameters & 0E-b & Std. Deviation \\
& Absolute & 5,73726762 \\
Most Extreme Differences & Positive &, 067 \\
& Negative &, 067 \\
Kolmogorov-Smirnov Z & &,- 056 \\
Asymp. Sig. (2-tailed) & &, 933 \\
\end{tabular}

a. Test distribution is Normal.

b. Calculated from data.

Sumber : Hasil Penelitian, 2019 (Data Diolah) 
P-ISSN 2580 - 7781

E-ISSN 2615 - 3238

Data tabel di atas dapat di simpulkan bahwah nilai Asymp. Sig. (2-tailed) sebesar 0.349 lebih besar dari 0.05 maka dengan demikian data tersebut berdistribusi normal.

\section{Uji Multikolineritas}

Tabel Uji Multikolinieritas

\begin{tabular}{|ll|r|c|}
\hline \multicolumn{3}{|c|}{ Coefficients $^{\mathbf{a}}$} \\
\hline \multirow{2}{*}{ Model } & \multicolumn{2}{|c|}{ Collinearity Statistics } \\
\cline { 3 - 4 } & & Tolerance & \multicolumn{1}{c|}{ VIF } \\
\hline \multirow{2}{*}{1} & KEPEMIMPINAN &, 999 & 1,001 \\
& BUDAYA ORGANISASI &, 987 & 1,013 \\
& KOMPETENSI &, 988 & 1,012 \\
\hline
\end{tabular}

a. Dependent Variable: KINERJA

Sumber : Hasil Penelitian, 2019 (Data Diolah)

Dari tabel di atas dapat dilihat nilia tolerance tiap variabel independent sebagai Kepemimpinan $\mathrm{X}_{1}=0.999$, Budaya Organisasi $\mathrm{X}_{2}=0.987$, Kompetensi $\mathrm{X}_{3}=0.988$ lebih besar dari 0.1 , sedangkan nilai VIF tiap variabel independet sebesar Kepemimpinan $\mathrm{X}_{1}=1.001$, Budaya Organisasi $\mathrm{X}_{2}=1.013$, Kompetensi $\mathrm{X}_{3}=1.012$ lebih kecil dari 10, maka data tersebut dinyatakan terbebas dari multikolinieritas.

\section{Uji Heterokedastisitas}

\section{Gambar Grafik Scatter Plot}

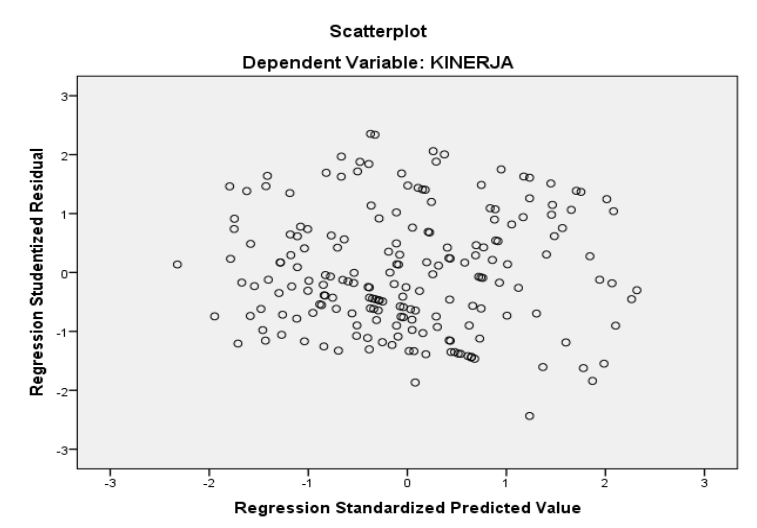

Sumber : Hasil Penelitian, 2019 (Data Diolah) 
P-ISSN 2580 - 7781

E-ISSN 2615 - 3238

Dari gambar grafik di atas dapat di lihat bahwa data tersebut menyebar tidak beratur dengan tidak membentuk suatu pola tertentu dan menjauhi titik 0 , maka data tersebut dinyatakan terbebas dari hetereokedastisitas.

\section{Hasil Uji Glejser}

Coefficients $^{\mathrm{a}}$

\begin{tabular}{|c|c|c|c|c|c|c|}
\hline \multirow{2}{*}{\multicolumn{2}{|c|}{ Model }} & \multicolumn{2}{|c|}{ Unstandardized Coefficients } & \multirow{2}{*}{$\begin{array}{c}\text { Standardized } \\
\text { Coefficients } \\
\text { Beta }\end{array}$} & \multirow[t]{2}{*}{$\mathrm{T}$} & \multirow[t]{2}{*}{ Sig. } \\
\hline & & $B$ & Std. Error & & & \\
\hline \multirow{4}{*}{1} & (Constant) & ,793 & 1,780 & & ,445 & ,656 \\
\hline & KEPEMIMPINAN & ,038 & ,036 & ,074 & 1,036 & ,302 \\
\hline & BUDAYA ORGANISASI &, 061 & ,035 & ,126 & 1,743 & ,083 \\
\hline & KOMPETENSI & ,033 & ,033 & ,072 & ,999 & ,319 \\
\hline
\end{tabular}

a. Dependent Variable: RES2

Sumber : Hasil Penelitian, 2019 (Data Diolah)

1. Variabel kepemimpinan (X1) memiliki 0,302 dari hasil uji heteroskedastisitas nilai signifikansi memiliki lebih besar dari 0.05 $(0,309>0,05)$ maka tidak terjadi gejala heterokedastisitas.

2. Variabel Budaya Organisasi (X2) memiliki 0,083 dari hasil uji heteroskedastisitas nilai signifikansi memiliki lebih besar dari 0,05 $(0,083>0,05)$ maka tidak terjadi gejala heterokedastisitas.

3. Variabel Kompetensi (X3) memiliki 0.319 dari hasil uji heteroskedastisitas memiliki lebih besar dari $0,05(0.319>0,05)$ maka tidak terjadi gejala heteroskedastisitas. 
P-ISSN 2580 - 7781

E-ISSN 2615 - 3238

\section{Analisis Regresi Linear Berganda}

a) Model Penelitian

\section{Analisis Regresi Linier Berganda}

Coefficients $^{a}$

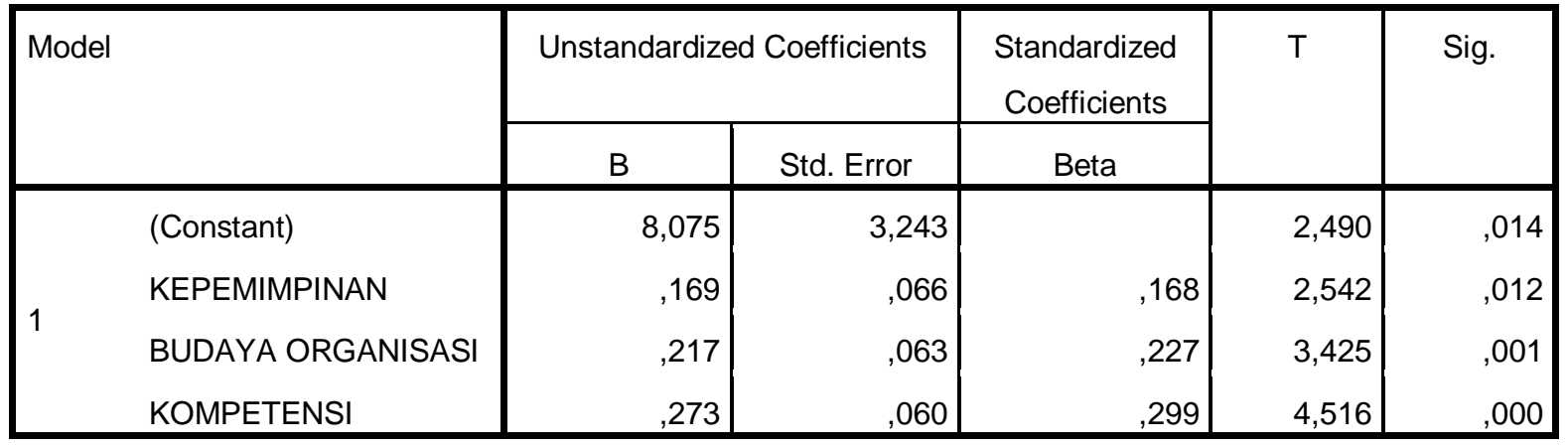

a. Dependent Variable: KINERJA

Sumber : Hasil Penelitian, 2019 (Data Diolah)

Kinerja $=8.075+0.169$ Kepemimpinan +0.217 Budaya Organisasi $+0,273$

\section{Kompetensi $+\mathbf{0 . 0 5}$}

Pada tabel di atas menjelaskan bahwa persamaan regresi tersebut mempunyai makna sebagai berikut:

1. Nilai konstanta a sebesar 8,075 diartika bahwa jika tidak terdapat variabel kepemimpinan $(\mathrm{X} 1)$, budaya organisasi $(\mathrm{X} 2)$, dan kompetensi $(\mathrm{X} 3)=0$ maka kinerja akan bernilai sebesar 8,075

2. Variabel kepemimpinan (X1) sebesar 0,169 yang diartikan bahwa setiap kenaikan variabel kepemimpinan sebesar 1 satuan, maka pada nilai kinerja akan naik 0,169 satuan dengan asumsi bahwah variabel lain tetap.

3. Variabel budaya organisasi (X2) sebesar 0,217 yang diartikan bahwa setiap kenaikan variabel budaya organsisasi sebesar 1 satuan, maka pada nilai kinerja akan naik 0,217 satuan dengan asumsi bahwa variabel lain tetap.

4. Variabel kompetensi (X3) sebesar 0,273 yang diartikan bahwa setiap kenaikan variabel kompetensi sebesar 1 satuan, maka pada nilai kinerja akan naik 0,273 satuan dengan asumsi bahwa variabel lain tetap. 
b) Koefisiensi Determinasi Hipotensi $\left(\mathbf{R}^{2}\right)$

\section{Koefisiensi Determinasi Hipotesis}

\begin{tabular}{|l|r|r|r|c|}
\hline Model & $R$ & $R$ Square & $\begin{array}{c}\text { Adjusted R } \\
\text { Square }\end{array}$ & $\begin{array}{c}\text { Std. Error of the } \\
\text { Estimate }\end{array}$ \\
\hline 1 &, $425^{\mathrm{a}}$ &, 180 &, 167 & 5,783 \\
\hline
\end{tabular}

a. Predictors: (Constant), KOMPETENSI, KEPEMIMPINAN, BUDAYA ORGANISASI

b. Dependent Variable: KINERJA

Sumber : Hasil Penelitian, 2019 (Data Diolah)

Berdasarkan tabel di atas bahwa dapat disimpulkan :

a) $\mathrm{R}=0.425$ berarti hubungan (corelation) antara variabel kepemimpinan, budaya organisasi, kompetensi terhadap variabel kinerja tinggi

b) Nilai Koefisien Adjusted $R$ Square (R Square) adalah sebesar 16,7\%. hal ini menunjukan bahwa variasi variabel kinerja (Y) dapat dijelaskan oleh variabel kepemimipinan $\left(\mathrm{X}_{1}\right)$, budaya organisasi $\left(\mathrm{X}_{2}\right)$ dan variabel kompetensi $\left(\mathrm{X}_{3}\right)$ sedangkan sisanya $83,3 \%$ adalah variabel bebas lainnya yang tidak di jelaskan dalam penelitian ini.

\section{Pengujian Hipotesis Secara Simultan (Uji F)}

\section{Hasil Pengujian Hipotesis Secara Simultan}

\begin{tabular}{|rl|r|r|r|r|r|}
\hline \multicolumn{1}{|l|}{ Model } & & Sum of Squares & \multicolumn{1}{c|}{ Df } & Mean Square & \multicolumn{1}{c|}{ F } & Sig. \\
\hline \multirow{2}{*}{1} & Regression & 1390,268 & 3 & 463,423 & 13,859 &, $000^{\mathrm{b}}$ \\
& Residual & 6319,918 & 189 & 33,439 & & \\
& Total & 7710,187 & 192 & & & \\
\hline
\end{tabular}

a. Dependent Variable: KINERJA

b. Predictors: (Constant), KOMPETENSI, KEPEMIMPINAN, BUDAYA ORGANISASI Sumber : Hasil Penelitian, 2019 (Data Diolah)

Berdasarkan Tabel di atas dapat dilihat bahwa $F_{\text {hitung }}$ adalah sebesar 13.856 lebih besar dari $\mathrm{F}_{\text {tabel }}$ yaitu 2.65 dengan sig $0.000<0.05$. hal ini posisi titik uji 
P-ISSN 2580 - 7781

E-ISSN 2615 - 3238

signifikansi berada pada wilayah penolakan $\mathrm{H}_{\mathrm{o}}$ atau di simpulkan $\mathrm{H}_{1}$ diterima. Dengan demikian kepemimpinan $\left(\mathrm{X}_{1}\right)$, budaya organisasi $\left(\mathrm{X}_{2}\right)$ dan kompetensi $\left(\mathrm{X}_{3}\right)$ secara simultan berpengaruh positif dan signifikan terhadap kinerja (Y) pada PT. Telkom Akses Witel Medan.

\section{Pengujian Hipotesis Secara Parsial ( Uji t )}

\section{Hasil pengujian Hipotesis Secara Parsial}

\begin{tabular}{|c|c|c|c|c|c|c|}
\hline \multicolumn{7}{|c|}{ Coefficients $^{a}$} \\
\hline \multirow{2}{*}{\multicolumn{2}{|c|}{ Model }} & \multicolumn{2}{|c|}{ Unstandardized Coefficients } & \multirow{2}{*}{$\begin{array}{c}\text { Standardized } \\
\text { Coefficients } \\
\text { Beta }\end{array}$} & \multirow[t]{2}{*}{$\mathrm{T}$} & \multirow[t]{2}{*}{ Sig. } \\
\hline & & B & Std. Error & & & \\
\hline \multirow{4}{*}{1} & (Constant) & 8,075 & 3,243 & & 2,490 & ,014 \\
\hline & KEPEMIMPINAN &, 169 & ,066 &, 168 & 2,542 &, 012 \\
\hline & BUDAYA ORGANISASI & ,217 & ,063 & ,227 & 3,425 &, 001 \\
\hline & KOMPETENSI & ,273 & ,060 & ,299 & 4,516 &, 000 \\
\hline
\end{tabular}

a. Dependent Variable: KINERJA

Sumber : Hasil Penelitian, 2019 (Data Diolah)

Berdasarkan tabel di atas menunjukan bahwa:

1. Variabel pengaruh kepemimpinan $\left(\mathrm{X}_{1}\right)$ memiliki $\mathrm{t}_{\text {hitung }} 2.542$ dan nilai $\mathrm{t}_{\text {tabel }}$ sebesar 1.652 maka nilai $t_{\text {hitung }}>t_{\text {tabel }}(2.542>1.652)$ dengan nilai signifikan sebesar $0.012<0.05$. Sehingga hasil penelitian yang di peroleh maka menolak $\mathrm{H}_{0}$ dan menerima $\mathrm{H}_{\mathrm{a}}$, dengan demikian dapat di simpulkan bahwa variabel kepemimpinan $\left(\mathrm{X}_{1}\right)$ secara parsial berpengaruh positif dan signifikan terhadap kinerja karyawan PT. Telkom Akses Witel Medan.

2. Variabel budaya organisasi $\left(\mathrm{X}_{2}\right)$ memiliki $\mathrm{t}_{\text {hitung }} 3.425$ dan nilai $\mathrm{t}_{\text {tabel }}$ sebesar 1.652 maka nilai $t_{\text {hitung }}>t_{\text {tabel }}(3.425>1.652)$ dengan nilai signifikan sebesar $0.001<0.05$. Sehingga hasil peneliti yang di peroleh maka menolak $\mathrm{H}_{0}$ dan menerima $\mathrm{H}_{\mathrm{a}}$, dengan demikian dapat di simpulkan bahwa variabel budaya organisasi $\left(\mathrm{X}_{2}\right)$ secara parsial berpengaruh positif dan signifikan terhadap kinerja karyawan PT. Telkom Akses Witel Medan. 
3. Variabel Kompetensi $\left(\mathrm{X}_{3}\right)$ memiliki $\mathrm{t}_{\text {hitung }} 4.516$ dan nilai $\mathrm{t}_{\text {tabe }} \mathrm{l}$ sebesar 1.652 maka nilai $t_{\text {hitung }}>t_{\text {tabel }}(4.516>1.652)$ dengan nilai signifikasi sebesar $0.000<0.05$. Sehingga hasil peneliti yang di peroleh maka menolak $\mathrm{H}_{0}$ dan menerima $\mathrm{H}_{\mathrm{a}}$, dapat disimpulkan bahwa variabel kompetensi $\left(\mathrm{X}_{3}\right)$ secara parsial berpengaruh positif dan signifikan terhadap kinerja karyawan PT. Telkom Akses Witel Medan.

\section{Pembahasan}

\section{Pengaruh Kepemimpinan $\left(\mathrm{X}_{1}\right)$ Terhadap Kinerja Karyawan (Y)}

Pada hasil pengujian secara parsial (Uji t) hal ini dapat dilihat bahwa kepemimpinan $\left(\mathrm{X}_{1}\right)$ memiliki nilai $\mathrm{t}_{\text {hitung }} 2.542$ dan nilai $\mathrm{t}_{\text {tabel }}$ sebesar 1.652 maka nilai $t_{\text {hitung }}>t_{\text {tabel }}(2.542>1.652)$ dengan nilai signifikan sebesar $0.012<0.05$. Dalam hasil penelitian ini membuktikan bahwa variabel kepemimpinan berpengaruh negatif dan signifikan terhadap variabel kinerja karyawan pada PT. Telkom Akses Witel Medan. Dapat di artikan bahwa kepemimipinan berpengaruh nyata untuk meningkatkan kinerja karyawan.

Dalam hasil penelitian yang sejalan dengan hasil yang di lakukan oleh Dihan (2017) yang mengatakan bahwa kepemimpinan berpengaruh positif dan signifikan terhadap kinerja karyawan.

\section{Budaya Organisasi $\left(\mathrm{X}_{2}\right)$ Terhadap Kinerja Karyawan (Y)}

Pada hasil pengujian secara parsial (Uji t) hal ini dapat dilihat bahwa budaya organisasi $\left(\mathrm{X}_{2}\right)$ memiliki nilai $\mathrm{t}_{\text {hitung }} 3.425$ dan nilai $\mathrm{t}_{\text {tabel }}$ sebesar 1.652 maka nilai $t_{\text {hitung }}>\mathrm{t}_{\text {tabel }}(3.425>1.652)$ dengan nilai signifikan sebesar $0.001<0.05$. Membuktikan bahwa variabel budaya organisasi sangat berpengaruh positif dan signifikan terhadap variabel kinerja karyawan PT. Telkom Akses Witel Medan. Dapat di artikan bahwa budaya organisasi terhdap variabel kinerja.

Dalam hasil penelitian ini sejalan dengan hasil penelitian yang di lakukan oleh Fadude (2019) yang mengatakan bahwa budaya organisasi berpengaruh positiv dan signifikan terhadap kinerja karyawan. 
P-ISSN 2580 - 7781

E-ISSN 2615 - 3238

\section{Kompetensi $\left(\mathbf{X}_{3}\right)$ Terhadap Kinerja Karyawan}

Pada hasil pengujian secara persial (Uji t) hal ini dapat dilihat kompetensi $\left(\mathrm{X}_{3}\right)$ memiliki nilai $\mathrm{t}_{\text {hitung }} 4.516$ dan nilai $\mathrm{t}_{\text {tabel }}$ sebesar 1.652 maka nilai $\mathrm{t}_{\text {hitung }}>\mathrm{t}_{\text {tabel }}$ (4.516>1.652) dengan nilai signifikan sebesar $0.000<0.005$. membuktikan bahwa variabel kompetensi sangat berpengaruh positif dan signifikan terhadap variabel kinerja karyawan PT. Telkom Akses Witel Medan. Dapat di artikan bahwa kompetensi sangat berpengaruh terhadap kinerja karyawan.

Dalam hasil penelitian yang sejalan dengan hasil penelitian yang di lakukan oleh Yuliana (2017) yang menunjukan bahwa kompetensi berpengaruh positif dan signifikan terhadap kinerja karyawan.

\section{Kepemimpinan, Budaya Organisasi, dan Kompetensi Terhadap}

\section{Kinerja}

Hasil pengujian secara simultan dapat dilihat bahwah nilai $F_{\text {hitung }}$ adalah sebesar 13.589 sedangkan $F_{\text {tabel }}$ sebesar 2.65 dari hasil ini di ketahui $F_{\text {hitung }}>F_{\text {tabel }}$ dan signifikan $0,000<0,05$, maka hasil penelitian menunjukan bahwa secara simutan $\mathrm{H}_{0}$ di tolak dan $\mathrm{H}_{\mathrm{a}}$ di terima. Hal ini menujukan bahwa kepemimpinan, budaya organisasi dan kompetensi berpengaruh positif dan signifikan terhadap kinerja karywan PT. Telkom Akses Witel Medan.

Dalam penelitian yang sejalan dilakukan oleh Eggy (2019) yang menunjukan bahwa seluruh variabel memiliki pengaruh yang signifikan terhadap kinerja karyawan.

\section{KESIMPULAN}

Berdasarkan analisis dan pembahasan, maka dalam penelitian ini dapat ditarik kesimpulan secara parsial menunjukan bahwa kepemimpinan, budaya organisasi dan kompetensi berpengaruh positif dan signifikan terhadap kinerja karyawan PT. Telkom Akses Witel Medan. Sementara secara simultan menunjukan bahwa kepemimpinan, budaya organisasi, kompetensi berpengaruh positif dan signifikan terhadap kinerja karyawan PT. Telkom Akses Witel Medan. 
P-ISSN 2580 - 7781

E-ISSN 2615 - 3238

\section{DAFTAR PUSTAKA}

Fahmi, Irham . 2016. Manajemen Sumber Daya Manusia Teori dan Aplikasi. Bandung: Alfabeta, Cv.

Fadude, F . D. 2019. Pengaruh Kepemimpinan, Budaya Organisasi, dan Kompetensi Terhadap Kinerja Karyawan PT. Bank Mandiri Cabang Belitung. Fakultas Ekonimi dan Bisnis jurusan Manajemen Universitas Sam Ratulungi. Jurnal Emba. Vol 5. No 1. September 2017.

Girniawan, Eggy. 2019. Pengaruh Kepemimpinan, Budaya Organisasi, Dan Kompetensi terhadap Kinerja Pegawai Kementrian Agraria Dan Tata Ruang / Bpn Kantor Pertanahan Kota Palembang. Fakultas Ekonomi jurusan Manajemen Universitas Sriwijaya. Vol. 17

Ganda, Benny. 2011. Pengaruh Gaya Kepemimpinan, Motivasi Pelatihan dan Disiplin Kerja terhadap Kinerja Karyawan PT. Surya Makmur Agung Lestari. Fakultas Ekonomi Universitas Semarang.

Noor, Juliansyah. 2017. Metodologi Penelitian: Skripsi, Tesis, Disertai dan Karya Iilmiah. Jakarta. Prenadamedia Group.

Provita, Dihan. 2017. Pengaruh Kepemimpinan, Budaya Organisasi, Motivasi, Terhadap Kepuasan Kerja Dan Kinerja Karyawan Pada Dinas Pemerintahan Desa Kabupaten Lumanjang ( PEMDES). Fakultas Ekonomi dan Bisnis, Universitas Brawijaya. Vol. 17. No.2.

Sutrisno, Edy. 2018. Budaya Organisasi. Jakarta. Prenadamedia Group.

Umam, Khaerul. 2018. Perilaku Organisasi. Bandung. Cv Pustaka Setia.

Wibowo. 2017. Manajemen Kinerja. Depok. PT Rajagrfindo Persada.

Yuliana. 2017. Pengaruh Kompetensi dan Motivasi Kerja Terhadap Kinerja Karyawan Perusahaan Pada PT. Haluan Star Logistic. Jurnal Ilmiah Manajemen Bisnis. Vol. 17. No 2. 